\title{
Students' Satisfaction towards the Quality of Education between Constituent Campus and Affiliated Campus of Tribhuvan University
}

\author{
a Govinda Prasad Dhungana \\ Ph D scholars \\ Dean Dayal Upadhaya Gorakhpur University, India
}

\begin{abstract}
Introduction

Worldwide, higher education is an important instrument for the construction of knowledge and development of human skills. Nepal has experienced a tremendous growth of Government, Public and Private Colleges as major contributors in providing higher education over the few decades but are facing rising issues related to lower enrollment and brain drain. Thus, aim of this study was to assess students' satisfaction towards the quality of education between Constituent Campus and Affiliated Campus of Tribhuvan University and determine its' prime domains.
\end{abstract}

\begin{abstract}
Methodology
Purposively, conducted a quantitative comparative research design study in one Constituent Campus and one Affiliated Campus of Tribhuvan University. Self-administered questionnaire tool, classified into Demographic information and Perception regarding student's satisfaction, were distributed to total 80 students, 40 each from Constituent Campus and Affiliated Campus using purposive sampling technique. Likert scale was used to measure perception of students toward the quality of education. Analyzed data in descriptive and inferential statistical technique using IBM SPSS 25 and AMOS 24 version software.
\end{abstract}

\section{Results}

Satisfaction towards quality of education was highly significant with academic environment $(\beta=1.14$, $p$-value $<0.001)$ followed by physical environment $(\beta=0.73$, p-value $<0.001)$, perceived quality education $(\beta=0.63$, p-value $<0.001)$ and services provided by different departments $(\beta=0.61$, p-value $<0.001)$.

\section{Conclusion}

Students' satisfaction towards the quality of education is poor in both Constituent and Affiliated Campus. However, Affiliated Campus students are more satisfied as compare to Constituent campus students. Well maintained classroom, good library facilities, positive attitude of the teaching faculties and appropriate services from departments should be focused for students' satisfaction regarding quality of education.

\section{Keywords: Higher Education, Students' Satisfaction, Constituent Campus, Affiliated Campus}

\section{Introduction}

Education promotes national unity by enhancing the degree of public awareness and plays a vital role in rising the nation especially in $21^{\text {st }}$ century (Awan, A. G., \& Zia, A. 2015). Furthermore, education provides platform for individuals to make them productive by acquiring necessary knowledge, skills and values in society and community, nationally and internationally. Higher education has been recognized worldwide, as an important instrument for the construction of knowledge and development of human skills. In today's competitive environment, delivery of high quality education, services and facilities can be viewed critically for successful existence of any higher educational institutes (Sohail, Rajadurai and Rahman, 2003).

Students' satisfaction is "the perception of enjoyment and accomplishment in the learning environment as well as a tool to evaluate the services and facilities provided by the institution" (Sweeney, J. C., \& Ingram, D. 2001; Elliott, K. M., \& Healy, M. A. 2001).Students' satisfaction is based on the quality of education, academic and physical facilities that students receive from different colleges and universities (Nguyen, N., \& LeBlanc, G. 2001, Hassanbeigi, A., 
\&Askari, J. (2010).Furthermore, students' satisfaction is a multi-dimensional process influenced by many factors like academic environment, quality of education, physical environment, services provided by different departments and others,presenting actual image of colleges and universities. According to Carey, K., Cambiano, R. L., \& De Vore, J. B. (2002) study satisfaction actually covers issues related to students' perception and experiences during the college years. Likewise, satisfaction towards the quality of education aidsin building self-confidence that helps students to develop the useful skills and acquire knowledge(Letcher, D. W., \&Neves, J. S. 2010).

Nepal has experienced a tremendous growth of Government, Public and Private Colleges over the few decades due to the increasing globalization of higher education in market. Nepalese students'institutional preferences for higher education depends on self or parent's decision as well as peer pressure.Higher education in Nepal is severely challenged by many factors such as economic, social, political, and moral changes resulting from population explosion, lack of resources, lack of qualified man power, inconsistent policies of various regimes, political instability, inefficient educational management system, wastage of resources, and poor implementation of policies/programme etc. (Bhusal TP; 2019). As a result, students' enrollment for higher education is continuously declining in Nepal. Whereas, enrollment for abroad studies is rigorously increasing due to dissatisfactory current education system, poor academics, unsatisfactory physical environment, lack of carrier opportunities and unemployment issues etc. Likewise, brain drain is also another rising issue lacking focus and proper solutions.

Government and Public Colleges are major contributors in providing higher education in Nepal, but are facing rising issues related to lower enrollment and brain drain. Thus, the aim of this study was to assess the students' satisfaction toward the quality of education between Constituent Campus and Affiliated Campus of Tribhuvan University and determine the prime domains of satisfaction towards quality of education.

\section{Methods}

Considering Bharatpur as a prime location for all major Constituent Campus and Affiliated Campus of Tribhuvan University. A quantitativecomparative research design was conducted in Constituent Campus and Affiliated Campus of Tribhuvan University, Chitwan. Purposively one each, Constituent Campus and one Affiliated Campus having same number of faculties and consistent number of student enrollment in each year were selected for the study. Total 80 students, 40 each from Constituent and Affiliated Campuswere selected from September $1^{\text {st }}$ to September $30^{\text {th }}, 2018$ using purposive sampling technique.

\section{Data collection tool and procedure}

The self-administrative questionnaires weredistributed. Questionnaire was classified into two parts: 1) Demographic information and 2) perception regarding student's satisfaction towards the quality of education. Likert scale ( $5=$ strongly satisfied, $4=$ satisfied, $3=$ dissatisfied, $2=$ =strongly dissatisfied and $1=$ not applicable) was used to measure perception of students toward the quality of education.

\section{Data analysis procedure}

Analyzed data in descriptive as well as inferential statistical techniqueusing IBM SPSS 25 and AMOS 24 version software. In descriptive statistics, mean score was used to describe the satisfaction toward the quality of education indicatinghigher the mean score higherthe satisfaction towards quality of education. In inferential statistic, Structure Equation Modeling (SEM) was used to test the hypothesis and significance between dependent factor (satisfaction toward the quality of education) and independent factors (physical environments, academic environments, perceived quality of education being taughtand service provided by different departments). One step SME was applied and guided by maximum likelyhood estimation to estimate the standard coefficient (regression coefficient and correlation coefficient).

\section{Reliablility and Validity}

Internal consistency of second part (perception) was measured by cronbatch's Alpha $(\alpha=0.835)$ which was acceptable (Shahyad, S et.al;2011). The SME was evaluated by examining fittness indices and variance explained estimates. Although, the measurement of fittness of tested model was to be done through examing of several indicies but current study included small sample size, thus $\chi^{2}$ was only used for goodness of fit. The result of the $\chi^{2}$ model was 331.5 with $164 \mathrm{df}(\mathrm{P}$ value $<0.001)$ which was acceptable when $\mathrm{n}<250$ and $12<$ statement $<30$ (Hair, J F et.al, 2010)

\section{Results \\ Demographic Characteristics}

More males were from Constituent Campus (57.5\%)than Affiliated Campus (55\%). Regarding faculties, more than three fourth $(77.5 \%)$ and Constituent Campus students were enrolled in science facultywhereas, two third $(60.0 \%)$ 
Affiliated Campus students were enrolled in management faculty. Likewise,same (52.5\%) percentages of studentswere from fourth year of Constituent Campus and first yearAffiliated Campus (table 1).

Table 1: Demographic characteristics of students

\begin{tabular}{|l|c|c|c|c|}
\hline \multirow{2}{*}{ Demographic Variables } & \multicolumn{2}{|c|}{ Constituent Campus } & \multicolumn{2}{c|}{ Affiliated Campus } \\
\cline { 2 - 5 } & Number & Percentage & Number & Percentage \\
\hline Sex & & & & \\
\hline Male & 23 & 57.5 & 22 & 55.0 \\
\hline Female & 17 & 42.5 & 18 & 45.0 \\
\hline Faculties & & & & \\
\hline Science & 31 & 77.5 & 1 & 2.5 \\
\hline Management & 6 & 15.0 & 24 & 60.0 \\
\hline Arts and Education & 3 & 5.5 & 15 & 37.5 \\
\hline Academic Year & & & & \\
\hline First year & 1 & 2.5 & 21 & 52.5 \\
\hline Second Year & 8 & 20.0 & 14 & 35.0 \\
\hline Third year & 10 & 25.0 & 3 & 7.5 \\
\hline Fourth year & 21 & 52.5 & 2 & 5.0 \\
\hline
\end{tabular}

Based on the perception about adequate academic environment during enrollment, 7 (17.5\%) of the students had enrolled in Constituent Campusand 24(60.0\%) in Affiliated Campus (figure 1).

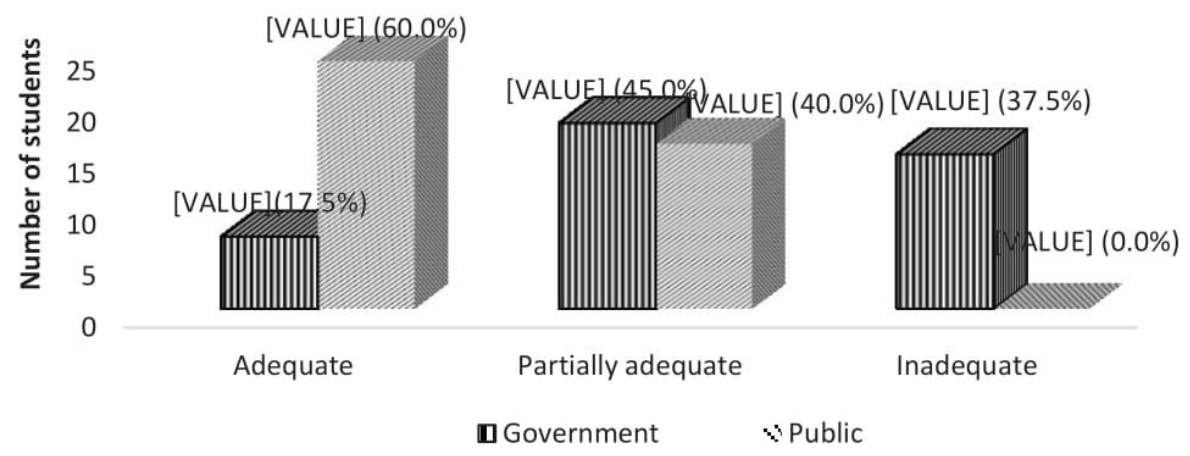

Figure 1: Perception of students about academic environment during enrollment.

\section{Students' satisfaction}

Students' satisfaction towards the quality of education was measured by mean score in four domains (Physical environment, Academic environment, Perceived quality of education being taught and Services provided by different departments) as perception of students. The mean score was ranked as descending order (lower the rankhigher the satisfaction).

Regarding the Physical Environment of college, mean score of the class room temperature maintenance was higher in Constituent Campus with $1^{\text {st }}$ rank than in Affiliated Campus with $4^{\text {th }}$ rank. Opposite to this Constituent Campus ranked $4^{\text {th }}$ and Affiliated Campus ranked $1^{\text {st }}$ for class room condition. Else, both collegesscored same rank in accordance to play ground, restroom, classroom maintenance and parking facilities.Both college students scored least rank as restroom, means lower satisfaction of condition of college restroom environment.

Likewise according to Academic Environment, Constituent Campusranked $1^{\text {st }}$ in reference to qualityresources available, contrary to this Affiliated Campus ranked $5^{\text {th }}$. Similarly, Affiliated Campus ( $1^{\text {st }}$ rank) studentswere highly satisfied with available library facilities whereasConstituent Campus students ( $3^{\text {rd }}$ rank) weren't. In addition, Affiliated Campus scored $2^{\text {nd }}$ rank and Constituent Campus scored $5^{\text {th }}$ rank for Extra facilities (like as hostel and canteen). 
Similarly, in context of Perceived quality of education being taught, Constituent Campuswas allotted first $\left(1^{\text {st }}\right)$ rank for receiving quality education whileAffiliated Campus was allotted least $\left(5^{\text {th }}\right)$ rank. On the other hand, Interest of teaching staff in students' progress, showeddissimilar results as Affiliated Campus ranked $1^{\text {st }}$ while Constituent Campus ranked $3^{\text {rd }}$.

Forservices provided by different departments, Constituent Campus students were highly ( $1^{\text {st }}$ rank) satisfied with service provided by finance department and Affiliated Campus students were less ( $2^{\text {nd }}$ rank) satisfied. Opposite to this, Affiliated Campus students were highly ( $1^{\text {st }}$ rank) satisfied by administrative department service but Constituent Campus students were less $\left(2^{\text {nd }}\right.$ rank) satisfied. Whereas, students from both the colleges were unsatisfied ( $4^{\text {th }}$ rank) with the service providedby IT department.

The overall satisfaction towards the quality of education between Constituent and Affiliated Campus was lower than average mean score (average mean score $=3$ ). However, satisfaction towards the quality of education was better in Affiliated Campus as compare to Constituent Campus (table 2).

Table 2: Comparisons between Students' Satisfactions towards the Quality of Education

\begin{tabular}{|c|c|c|c|c|c|}
\hline & \multirow{2}{*}{ Statements } & \multicolumn{2}{|c|}{ Constituent Campus } & \multicolumn{2}{|c|}{ Affiliated Campus } \\
\hline & & Mean \pm SD & Rank & Mean \pm SD & Rank \\
\hline Domain I & Physical Environment & & & & \\
\hline V1 & Playground condition & $2.20 \pm 1.20$ & 5 & $2.35 \pm 0.66$ & 5 \\
\hline $\mathrm{V} 2$ & Class room condition (light and ventilation) & $2.22 \pm 1.06$ & 4 & $3.05 \pm 0.60$ & 1 \\
\hline V3 & Restroom condition & $1.42 \pm 1.11$ & 6 & $2.22 \pm 0.77$ & 6 \\
\hline V4 & Maintenance of classroom (clean and well manage) & $2.25 \pm 1.13$ & 3 & $2.60 \pm 0.67$ & 3 \\
\hline V5 & Availability of parking facilities & $2.42 \pm 1.13$ & 2 & $2.95 \pm 0.78$ & 2 \\
\hline \multirow[t]{2}{*}{ V6 } & Maintenance of class room temperature & $2.60 \pm 0.87$ & 1 & $2.52 \pm 0.55$ & 4 \\
\hline & Total & $2.16 \pm 0.66$ & & $2.62 \pm 0.27$ & \\
\hline Domain II & Academic Environment & & & & \\
\hline V7 & Quality resources available & $2.15 \pm 0.95$ & 1 & $2.25 \pm 1.08$ & 5 \\
\hline V8 & Quality of laboratory facility & $2.15 \pm 1.05$ & 2 & $2.70 \pm 0.82$ & 3 \\
\hline V9 & Availability of computer and technology & $1.77 \pm 1.25$ & 4 & $2.47 \pm 0.84$ & 4 \\
\hline V10 & Library Facility & $1.95 \pm 1.07$ & 3 & $2.90 \pm 0.38$ & 1 \\
\hline \multirow[t]{2}{*}{ V11 } & Extra campus facilities (Hostel, canteen) & $1.43 \pm 1.28$ & 5 & $2.75 \pm 0.74$ & 2 \\
\hline & Total & $1.92 \pm 0.70$ & & $2.62 \pm 0.43$ & \\
\hline Domain III & Perceived quality of education & & & & \\
\hline V12 & Receive quality education & $2.55 \pm 0.63$ & 1 & $2.80 \pm 0.64$ & 5 \\
\hline V13 & Professionalism of lecture and tutors & $2.55 \pm 0.93$ & 2 & $2.87 \pm 0.61$ & 3 \\
\hline V14 & Perceived attitude of faculties during teaching & $2.25 \pm 1.01$ & 4 & $2.88 \pm 0.40$ & 2 \\
\hline V15 & Interest of teaching staff in my progress & $2.20 \pm 0.91$ & 5 & $2.95 \pm 0.32$ & 1 \\
\hline \multirow[t]{2}{*}{ V16 } & Accomplishment ability in lecture and tutors & $2.25 \pm 0.93$ & 3 & $2.83 \pm 0.59$ & 4 \\
\hline & Total & $2.31 \pm 0.56$ & & $2.87 \pm 0.30$ & \\
\hline Domain IV & Services Provided by different Departments & & & & \\
\hline V17 & Administrative Department & $2.22 \pm 0.69$ & 2 & $2.78 \pm 0.58$ & 1 \\
\hline V18 & Finance Department & $2.36 \pm 0.77$ & 1 & $2.78 \pm 0.66$ & 2 \\
\hline V19 & Information Technology (IT) Department & $1.15 \pm 1.05$ & 4 & $2.20 \pm 0.97$ & 4 \\
\hline \multirow[t]{2}{*}{ V20 } & Recreational Department & $1.43 \pm 1.09$ & 3 & $2.32 \pm 0.82$ & 3 \\
\hline & Total & $1.89 \pm 0.66$ & & $2.50 \pm 0.46$ & \\
\hline
\end{tabular}

\section{Relationship with Satisfaction towards the Quality Education with Domains}

The standardized parameters (correlation and regression) were estimated using SEM. It showed significantly positive relationship for student satisfaction toward the quality education with four major domains (Physical environment, Academic environment, Perceived quality teaching and Services provided by different departments) with p-value $<0.001$. 
The finding showed strong positive correlation $(\mathrm{r}=0.81)$ between Physical environment and Academic environment where as weak correlation $(\mathrm{r}=0.24)$ between Physical environment and Services provided by different departments.

The results revealed that students ' satisfaction with the quality of education in each campus had a powerful relationship with the Physical and Academic environments followed by an Academicenvironments with different departments providing service. However, Service provided by various departments had relatively low degree of relationship with the Physical environment(table 3 and figure 2).

Table 3: Relationship between Domains of Satisfaction towards the Quality Education

\begin{tabular}{lllll}
\hline Correlation & Domain I & Domain II & Domain III & Domain IV \\
\hline Domain I & 1 & & & \\
Domain II & 0.81 & 1 & & \\
Domain III & 0.66 & 0.71 & 1 & \\
Domain IV & 0.24 & 0.72 & 0.44 & 1 \\
\hline
\end{tabular}

In regards to Physical domain the standardized regression coefficient was more $(\beta=0.63)$ formaintenance of classroom (clean and well manage) and least $(\beta=0.36)$ for classroom temperature maintenance. It indicates that students were highly satisfied with clean and well managed class room and gave less priority for classroom temperature. Similarly, in context to academic environment, the standardized regression coefficient was more $(\beta=0.71)$ for library facility and less $(\beta=0.36)$ for resources availability. This finding showed that students were more satisfied with the library facility in college than resources availability. Regarding, Perceived quality education, standardized regression coefficient was higher $(\beta=0.72)$ for perceived attitude of faculties during teaching and lower $(\beta=0.33)$ for quality of education received by students. Thus, student's satisfactionwas more dependent onteacher's behaviour in classroom rather than quality of education provided to them. Likewise, from the prospective of Services provided by different departments, standardized regression coefficient was higher $(\beta=0.87)$ for IT department and least $(\beta=0.56)$ for Administrative Department. It reveals that, students were highly satisfied receiving the quality services from IT department than administrative department services (figure 2).

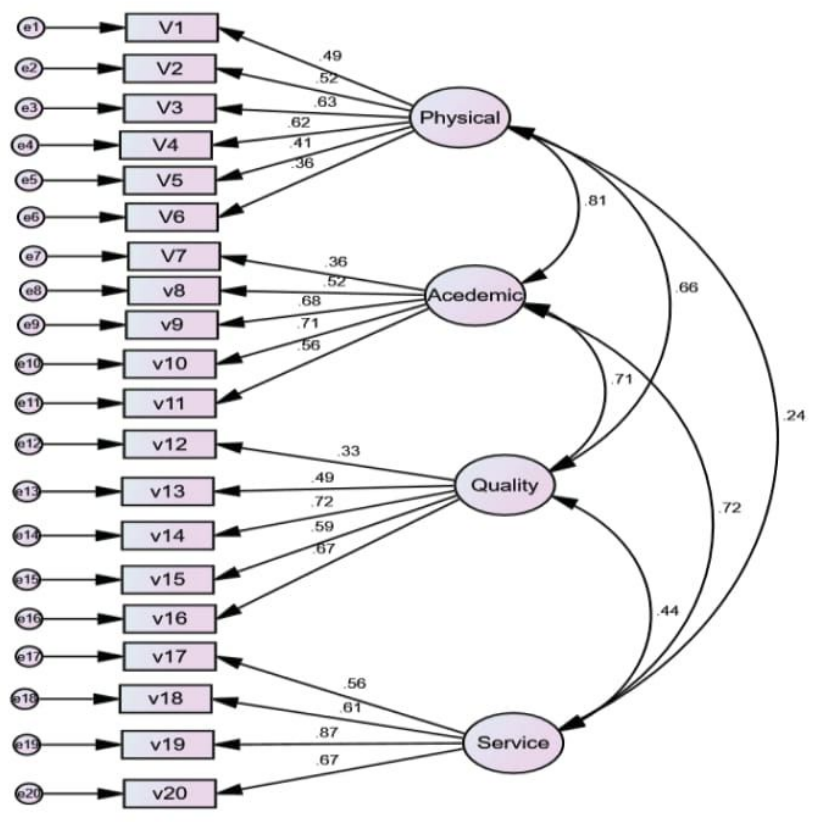

Figure2: Relationship between domains of students' satisfaction toward quality education

Satisfaction towards quality education was highly significant with Academic environment $(\beta=1.14$, p-value $<0.001)$ followed by Physical environment $(\beta=0.73$, $p$-value $<0.001)$, Perceived quality education $(\beta=0.63$, p-value $<0.001)$ and Services provided by different departments $(\beta=0.61$, p-value $<0.001)$. Findings reveled that, Academic environment was the $1^{\text {st }}$ priority of students than Physical environment, Perceived quality education and Services provided by different departments for greater satisfaction(figure 3). 


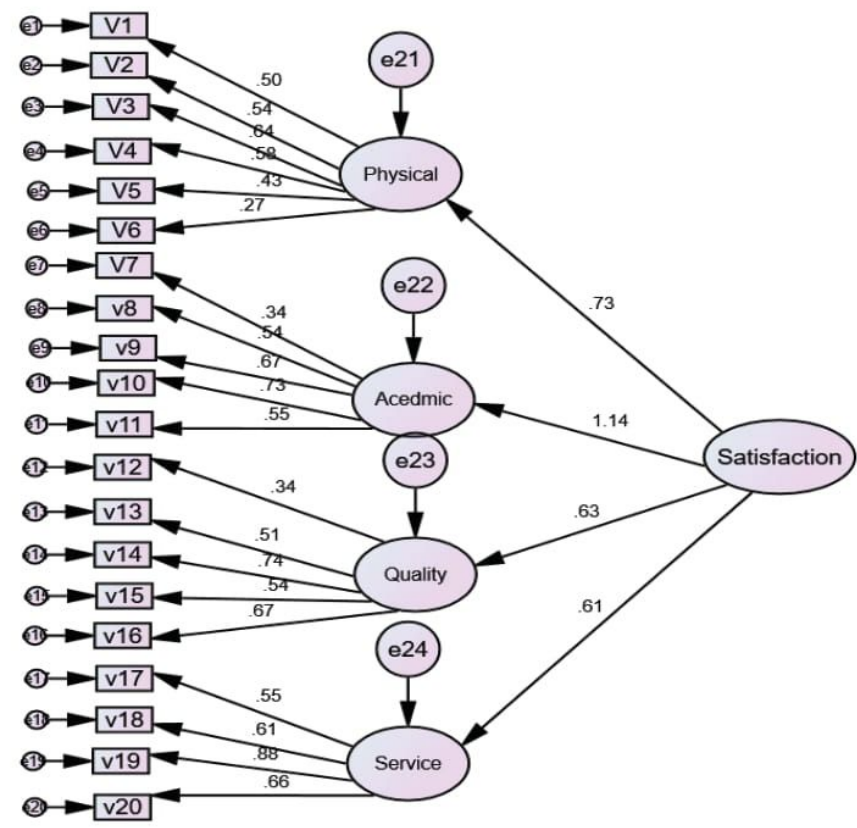

Figure 3: Factors affecting the students' satisfaction toward the quality education

\section{Discussion}

The present study has attempted to identify satisfaction towards the quality education between Constituent and Affiliated Campus of Tribhuvan University andto determine prime domains of quality education. The findings of present study showed that the overall satisfaction towards the quality of education waslow in both Constituent and Affiliated Campus. Student's satisfaction toward the quality of education requires well managed class room, sufficient library facilities, good attitudeof faculty members/tutors and good services provided by IT department. PokharelA K et.al. (2013) study showed similar findings, according to the findingsproper learning environment, well equipped library, laboratory, toilets, extra-curricular activities and healthy environment inside the institutions are essential factors for satisfaction towards the quality of education. Findings of this study was supported bySapri et al. (2009) study, which explored some important factors such as facilities of library, lab, sport and canteen etc., for the satisfaction of the students in higher education institution. Mc Arthur et.al. (2012) study found that satisfaction of student was correlated with the perceived behaviour of faculty in classroom. Academic environment in classes is also the important factor which determines the satisfaction of the students with quality education and their attachment to the institution (DeShields Jr et.al.2005). On the other hand, Upadhyay, J. P. (2018) study showed contradictory findings, it is concluded that higher education in Nepal has been effective to satisfy different stakeholders as well as has been able to meet the objectives for which it was envisioned.

Overall findings of the present study showed thatstudents from Affiliated Campus were more satisfied as compare to Constituent Campus. This may have resulted from availability of better facilities such as Physical environment, Academic environment, Perceived quality education provided by faculty and Services provided in different departmentsrendered by Affiliated Campusas compared to Constituent Campus.It may also happen, Affiliated Campus had recently established, so it is better Physical environment. Likewise, faculty/ administrative staff are more concerned with learners because they are the source of revenue in Affiliated Campus but in Constitute Campus both conditions may not be true.Results may also have been influenced by variation in the study participants from Constituent Campus and Affiliated Campus where majority of Affiliated Campus students were from first $\left(1^{\text {st }}\right)$ yearwhereas Constituent Campus students were from final $\left(4^{\text {th }}\right)$ year. So, Constituent Campus studentsmay have been weak in perceiving the academic environment, teacher's attitude in class room and provided IT department services. A finding of Uprety, R. et,al. (2014) also highlighted thatthere is a strong association between college culture dimensions and student satisfaction towards the quality education to achieve better organizational performance. Napitupulu, D (2018) study revealed similar findings, showing the quality of campus service facilities had an effect on students' satisfaction where higher number of students' satisfaction is considered noble productivity and can help to achieve the goal of that organization. Hence, students' satisfaction is determined as a strong achievement of any organization. 


\section{Conclusion}

The overall students' satisfaction toward the quality of education is poor in both Constituent Campus and Affiliated Campus. However, Affiliated Campusstudents are more satisfied as compare to Constituent Campus students. The main domains of satisfaction are Physical environment, Academic environment, Perceived quality education provided by faculty members and services provided by different departments. To improve the satisfaction regarding the quality education, well maintained class room, good library facilities, positive attitude of the faulty members in class room rather than teaching quality education and appropriate services provided in different departments are key factors of students' satisfaction regarding quality of education.

\section{Limitation of Study}

The purposive selection of study area as well as small sample size may not ensure all validity criteria of Structure Equation Modeling. Findings of this study may not provide a complete picture of students' satisfaction towards the quality of education between Constituent Campus andAffiliated Campus of Tribhuvan University to generalize at national level.

\section{Acknowledgement}

We would like to show our gratitude to Mr. KeshavDhungana, Mr. PurnaKhattri and Mr. Prasiddha Sharma $4^{\text {th }}$ year B. Sc. students of Birendra Multiple Campus, who collected data and added valuable contribution in accomplishment of this research work.

\section{Funding of Research}

Have not received any financial support from external sources.

\section{Conflict of interest}

No conflict of interest is declared.

\section{References}

Awan, A. G., \& Zia, A. (2015). Comparative Analysis of Public and Private Educational Institutions: A case study of District Vehari-Pakistan. Journal of Education and Practice, 6(16), 122-130.

Bhusal T.P. (2019). Nepal online education and career resource. Retrieved from http://www.educatenepal.com/ contributors/articles/higher-education-in-nepal-issues-and-challenges

Carey, K., Cambiano, R. L., \& De Vore, J. B. (2002, July). Student to faculty satisfaction at a Midwestern university in the United States. In The 25th HERSDA Annual Conference.

DeShields Jr, O. W., Kara, A., \&Kaynak, E. (2005). Determinants of business student satisfaction and retention in higher education: applying Herzberg's two-factor theory. International journal of educational management, 19(2), 128-139.

Elliott, K. M., \& Healy, M. A. (2001). Key factors influencing student satisfaction related to recruitment and retention. Journal of marketing for higher education, 10(4), 1-11.

Hair, J. F., Black, W. C., Babin, B. J., Anderson, R. E., \& Tatham, R. (2010). L. (2010). Multivariate data analysis. Pearson.

Hassanbeigi, A., \&Askari, J. (2010). A study of the most important risk factors of motivational deficiencies in university students. Procedia-Social and Behavioral Sciences, 5, 1972-1976.

Letcher, D. W., \&Neves, J. S. (2010). Determinants of undergraduate business student satisfaction. Research in Higher Education Journal, 6, 1.

McArthur, J. A., \&Bostedo-Conway, K. (2012). Exploring the relationship between student-instructor interaction on Twitter and student perceptions of teacher behaviors. International Journal of Teaching and Learning in Higher Education, 24(3), 286-292.

Napitupulu, D., Rahim, R., Abdullah, D., Setiawan, M. I., Abdillah, L. A., Ahmar, A. S., \&Pranolo, A. (2018). Analysis of student satisfaction toward quality of service facility. In Journal of Physics: Conference Series (Vol. 954, No. 1, p. 012019). IOP Publishing.

Nguyen, N., \& LeBlanc, G. (2001). Image and reputation of higher education institutions in students' retention decisions. International Journal of Educational Management, 15(6), 303-311.

Pokharel, A. K., \&Paudel, J. (2013). Cultural factors causing differences in quality education. Researcher: A Research Journal of Culture and Society, 1(2), 1-10. 
SadiqSohail, M., Rajadurai, J., \&Azlin Abdul Rahman, N. (2003). Managing quality in higher education: a Malaysian case study. International Journal of Educational Management, 17(4), 141-146.

Sapri, M., Kaka, A., \& Finch, E. (2009). Factors that influence student's level of satisfaction with regards to higher educational facilities services. Malaysian Journal of Real Estate, 4(1), 34-51.

Shahyad, S., Besharat, M. A., Asadi, M., Alipour, A. S., \& Miri, M. (2011). The relation of attachment and perceived social support with life satisfaction: structural equation model. Procedia-Social and Behavioral Sciences, 15 , 952-956.

Sweeney, J. C., \& Ingram, D. (2001). A comparison of traditional and web-based tutorials in marketing education: An exploratory study. Journal of Marketing Education, 23(1), 55-62.

Upadhyay, J. P. (2018). Higher Education in Nepal. Pravaha, 24(1), 96-108.

Uprety, R., \&Chhetri, S. B. (2014). College culture and student satisfaction. Journal of Education and Research, 4(1), $77-9$ 